\title{
EFEITO DA SALINIDADE NO DESENVOLVIMENTO LARVAL DE Echinaster echinophorus (LAMARCK 1816) (ECHINODERMATA: ASTEROIDEA)
}

\author{
NOBRE, C.C. \& L. S. CAMPOS-CREASEY \\ Universidade Santa Úrsula / Rua Jornalista Orlando Dantas, 59, Botafogo, Rio de \\ Janeiro, RJ, Brasil, CEP: 22231-010. e-mail: cacanobre@yahoo.com / \\ Isc_creasey@hotmail.com.br
}

\begin{abstract}
RESUMO
Amostras de Echinaster echinophorus (Lamarck 1816) (Echinodermata: Asteroidea) foram coletadas na região de Cabo Frio, Rio de Janeiro, Brasil. Os animais foram induzidos a desova em laboratório. Sucesso no crescimento, desenvolvimento, assentamento larval e metamorfose foram observados após os ovos terem sido submetidos a diferentes salinidades decrescendo de 34 psu a 10psu. Quanto menor a salinidade, menor o desenvolvimento larval e a taxa de sobrevivência. O desenvolvimento completo é possível em salinidades de até $25 \mathrm{psu}$. Um maior período de permanência no plâncton pode implicar em maiores chances de predação e menor sucesso no recrutamento.
\end{abstract}

Palavras Chave: Echinaster echinophorus, salinidade, desenvolvimento larval

\section{EFFECT OF SALINITY ON THE LARVAL DEVELOPMENT OF ECHINASTER ECHINOPHORUS(LAMARCK 1816) (ECHINODERMATA: ASTEROIDEA)}

\begin{abstract}
Samples of Echinaster echinophorus (Lamarck 1816) (Echinodermata: Asteroidea) were collected in Cabo Frio, Rio de Janeiro, Brazil. Animals were induced to spawn in the laboratory. Success in larval growth, development, settlement and metamorphosis were observed after exposing eggs to different salinities ranging from 34psu to 10psu. As salinity decreased the development was retarded, and survival rate was reduced. Full development was possible in salinities as low as $25 \mathrm{psu}$. The longer period spent in the plankton may result in higher chances of suffering predation and less success in recruitment.
\end{abstract}

Keywords: Echinaster echinophorus, salinity, larval development

\section{INTRODUÇÃO}

A estrela-do-mar Echinaster echinophorus (Lamarck, 1816) é comum na costa brasileira e pode ser encontrada em regiões estuarinas, especialmente no nordeste brasileiro (Kempf, 1966 e Tommasi, 1970). Asteróideos do gênero Echinasterincluem espécies polimorfas sendo que podem ocorrer hibridizações (Watts et al., 1982; Scheibling,
1982 e Clark \& Downey, 1992). E. echinophorus é registrada na literatura como ocorrendo do sul da Flórida até a Bacia de Campos-RJ (Tommasi, 1999). Apesar disso, coletas de exemplares dessa espécie vem ocorrendo também na região de Cabo Frio.

A presença de espécies de Echinaster, morfologicamente distintas, tem sido observada na área da Praia das Conchas em Cabo Frio, Rio de Janeiro (Campos-Creasey \& No- 
bre em preparação). Caracteristicamente, exemplares de E. echinophorus foram reconhecidos apresentando braços curtos e grossos, espinhos robustos, sem placas actinolaterais de acordo com Tommasi (1970 e 1999) (Figura 1).

Como E. echinophorus é uma espécie que pode ser encontrada em áreas de baixa salinidade (até 20 psu na região Nordeste Kempf, 1966), este trabalho teve como objetivos averiguar como diferentes salinidades afetam o desenvolvimento larval e sucesso de assentamento e metamorfose e verificar a salinidade mínima de tolerância dos embriões.

\section{MATERIAL E MÉTODOS}

Em setembro de 1999 foram coletados manualmente 10 exemplares de Echinaster echinophorus no costão rochoso da Praia das Conchas, localizada no município de Cabo Frio,

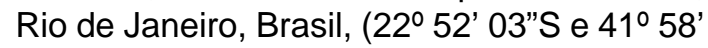
53 " W, Figura 2). No campo registrou-se a temperatura da água e a salinidade foi estimada com a utilização de um densímetro (precisão

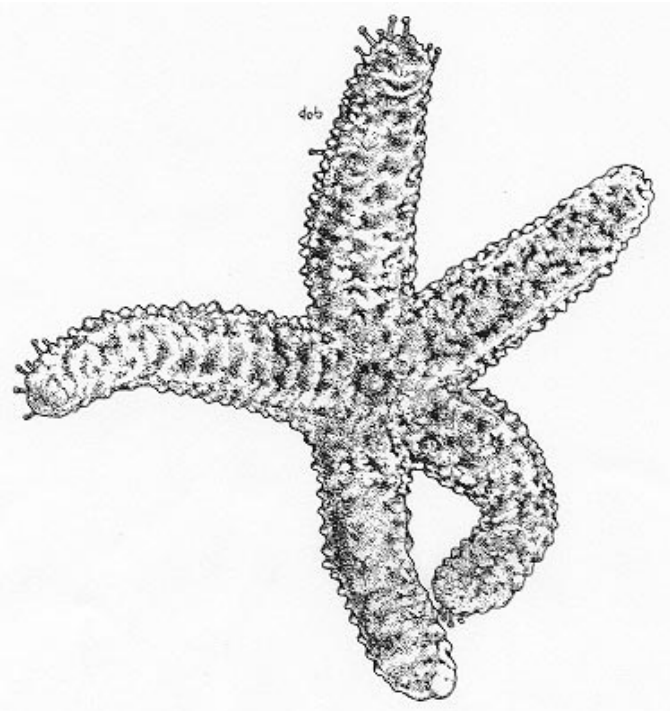

Figura 1: Echinaster echinophorus (Lamarck 1816) de 0,001 para gravidade específica e 0,5 para salinidade). Os animais foram levados para o laboratório e mantidos em aquário em condições de temperatura e salinidade semelhantes as do ambiente natural.

Os exemplares de E. echinophorus foram colocados individualmente em placas de Petri e induzidos a desova com uma injeção de solução salina ( $1 \mathrm{ml}$ de $0,5 \mathrm{M}$ de $\mathrm{KCl}$ ) nos interraios (Chen \& Run, 1988). Os gametas masculinos e femininos foram misturados com auxílio de seringas sem agulha. Os ovos ( $n=386)$, grandes ( $\pm 1 \mathrm{~mm}$ de diâmetro), visíveis a olho nu, foram separados em frascos cilíndricos de vidro (volume de $3 \mathrm{I}$, cada um), aerados e com a água do mar fracamente movimentada com a própria aeração.

Dois experimentos foram realizados ao mesmo tempo para o estudo do efeito da salinidade no desenvolvimento de $E$. echinophorus, sendo que os embriões e larvas receberam sete tratamentos. As diferentes salinidades nos dois experimentos foram medidas também com densímetro.

\section{Experimento 1}

Um frasco controle foi mantido com a mesma salinidade encontrada no campo no dia da coleta dos adultos, 33,5psu (tratamento 1). Outros 5 frascos foram mantidos com as salinidades $30,25,20,15$ e 10 psu, sendo estas constantes do início ao fim do experimento (tratamentos 2, 3, 4, 5 e 6). O final do teste foi definido como finalizado quando o estágio juvenil foi alcançado (28 dias).

\section{Experimento 2}

Um frasco foi utilizado para diluir a salinidade de 33.5 psu para 30 psu em 48 horas e depois em intervalos de 5 psu a cada 48 horas até alcançar a salinidade 10 psu. Depois foi feita uma diluição de 10 psu para 9 psu e de 9 psu para 8 psu num intervalo de 24 cada diluição. Este experimento (tratamento 7) foi realizado com a finalidade de verificar a salinidade 
mínima de tolerância dos embriões e se a salinidade mínima utilizada no experimento 1 foi adequada.

Todos os frascos foram mantidos em ambiente com ar condicionado, tal que a temperatura foi mantida constante $\left(t=23^{\circ} \mathrm{C}\right)$ no decorrer dos dois experimentos. A água dos frascos foi trocada diariamente por água do mar filtrada e diluída em água destilada em diferentes proporções, de acordo com a salinidade a ser alcançada. As larvas em suspensão eram retiradas cuidadosamente dos frascos por sucção com auxílio de seringas sem agulha, enquanto que as que se encontravam aderidas eram removidas gentilmente com auxílio de pincéis finos e colocadas em frascos limpos com a água renovada. As larvas de E. echinophorus são lecitotróficas, sendo estas de fácil manu- tenção sem a necessidade de inoculação de alimento (Hyman, 1955 e Kempf 1966).

O crescimento, desenvolvimento e mudanças morfológicas das larvas, nos dois experimentos, foram observados e registrados diariamente com auxílio de microscópio estereoscópico Leitz-Wetzlar com câmara clara.

\section{RESULTADOS}

A Tabela 1 representa de forma pictórica as diferentes fases de desenvolvimento de Echinaster echinophorus, submetidas às salinidades de 33,5 a 10 psu (Experimento 1). Observou-se que as mudanças iniciais na morfologia das larvas são mais lentas quando estas são submetidas às salinidade mais bai-

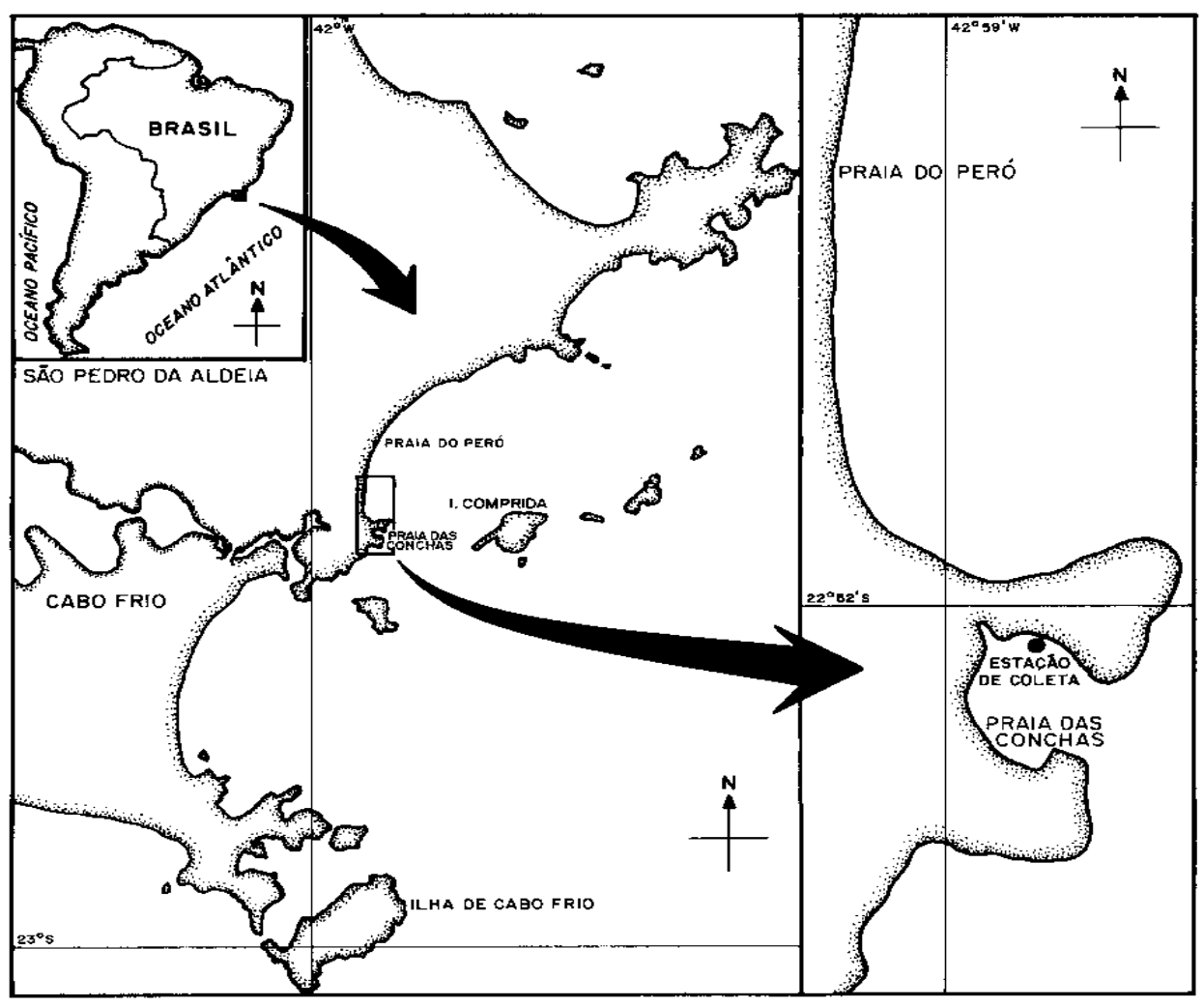

Figura 2: Mapa da Região de Cabo Frio apontando a estação de coleta na Praia das Conchas. 
Tabela 1: Representação pictórica do desenvolvimento larval de Echinaster echinophorus em diferentes salinidades ao longo do tempo.

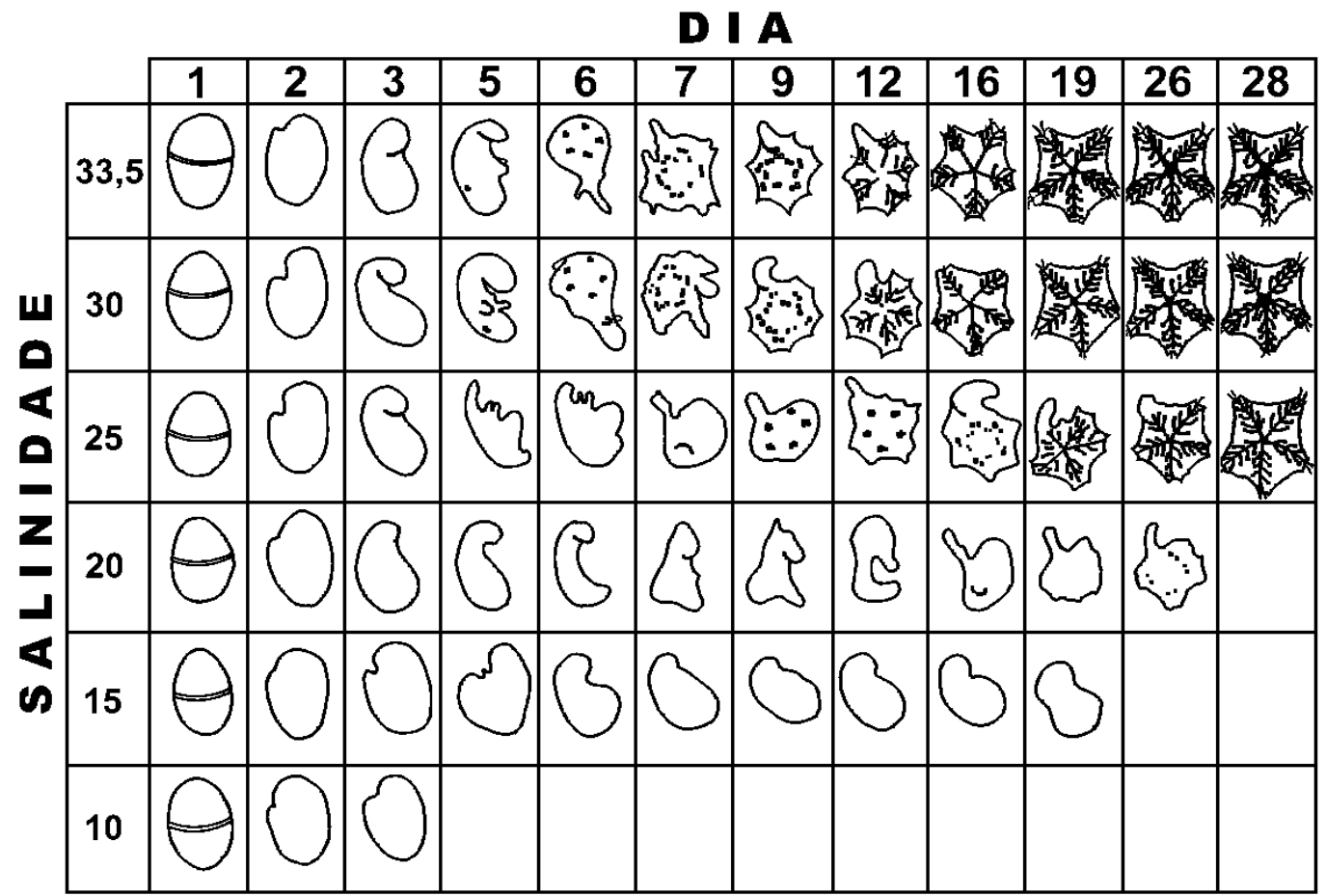

xas. A metamorfose iniciou-se no $6^{\circ} \mathrm{dia}$, em condição de salinidade 33.5 psu, e atingiu o estágio juvenil ao final de 19 dias (Figura 3). Em condição de salinidade 25 psu, o início da metamorfose ocorreu no $9^{\circ}$ dia, sendo que a mesma fase só pôde ser observada no $19^{\circ}$ dia sob condições de salinidade 20 psu. Em salinidades abaixo de 20 psu as larvas não ultrapassaram a fase de formação dos lobos braquiolares e morreram por volta do terceiro dia.

A taxa de mortalidade foi grande nos primeiros 5 dias de desenvolvimento em todos os frascos, com perda de 25 a 45 indivíduos por frasco. Sob condições de salinidades entre 25 e 33,5 psu a mortalidade foi mais intensa até $07^{\circ}$ dia, mas continuou ocorrendo até $o$ $17^{\circ}$ dia, quando restaram de 7 a 10 larvas por frasco, as quais continuaram seu desenvolvi- mento, até atingirem o estágio juvenil (Figura 4).

No frasco controle (salinidade $33,5 \mathrm{psu}$ ), as larvas atingiram o estágio juvenil no período de 19 dias. No primeiro dia de desenvolvimento após a fertilização, os ovos apresentavam forma circular a ovalada, coloração laranja vivo e tamanho médio de $1 \mathrm{~mm}(\mathrm{n}=386)$. Duas a 3 horas após a fecundação, foi possível observar a primeira divisão holoblástica ocorrendo. No $2^{\circ}$ dia os embriões alongaram-se discretamente, passando a ter movimento próprio em torno do eixo do corpo através de cílios. No $3^{\circ}$ dia as larvas tornaram-se mais ovaladas com uma extremidade mais robusta e outra mais afilada. No $4^{\circ}$ dia os lobos braquiolares já encontravam-se evidentes. No $5^{\circ}$ dia o hidróporo tornou-se visível e os lobos braquiolares apresentavam-se mais desenvolvidos, com formação 
de uma ventosa entre os lobos que permitiu o assentamento das larvas ao substrato. № $6^{\circ}$ dia as larvas comprimiram-se lateralmente, sendo possível observar o início da pentamerização. No $7^{\circ}$ dia o corpo tornou-se ainda mais comprimido e de forma circular com dois lobos braquiolares ainda evidentes. Na face oposta à da abertura do hidróporo formaram-se 5 pares de pés ambulacrais. No 9이 dia a pentamerização tornou-se mais evidente com o corpo apresentando forma de estrela e os pés ambulacrais tornando-se funcionais. Neste ponto a ventosa larval deixou de ser o órgão de fixação ao substrato. No $11^{\circ}$ dia os sulcos ambulacrais encontravam-se evidentes e mais 5 pares de pés ambulacrais formaram-se. Os lobos braquiais tornaram-se bem reduzidos. No $16^{\circ}$ dia mais 5 pares de pés ambulacrais surgiram, totalizando 3 pares em cada sulco. Os lobos braquiais desapareceram e a boca começou a se formar. Considerou-se o início do estágio juvenil o 19ํdia, nos indivíduos manti-

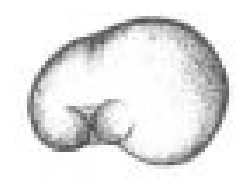

a

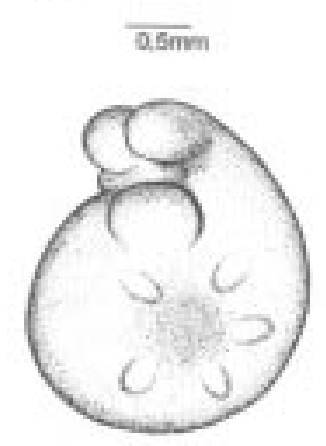

c

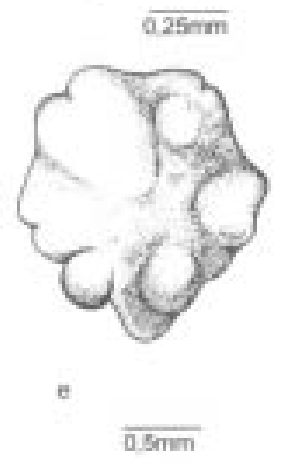

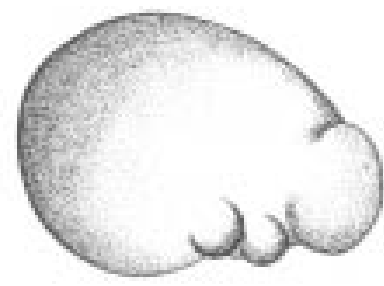

b

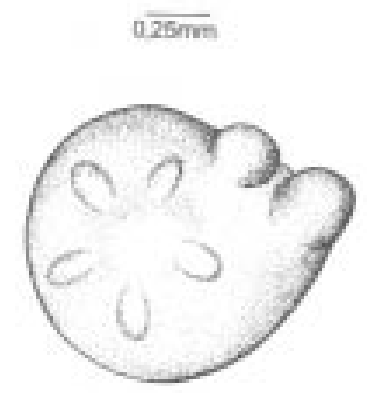

d

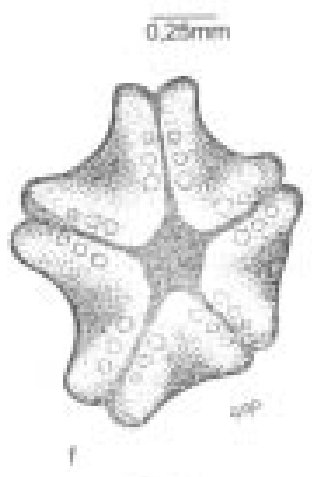

$0.25 \mathrm{~mm}$

Figura 3: Fases do desenvolvimento de E. echinophorus: a.) Larva lecitotrófica em salinidade 33,5; b.) início da metamorfose, torção dos lobos branquiais da larva; c.-d.) início da pentamerização visível; e.) lobo branquial ainda visível na pós larva, boca ainda não totalmente formada e, f.) estágio juvenil ao final de 19 dias de desenvolvimento, com ossículos da mandíbula prontos. 
dos em salinidade 33,5 , em que a boca estava totalmente aberta e 5 pares de pés ambulacrais foram observados, em cada sulco ambulacral.

No tratamento 7, a diluição gradual da salinidade permitiu a sobrevivência de larvas por um tempo maior (12 dias). Porém, as modificações morfológicas mais importantes ocorreram nos três primeiros dias do experimento sendo que, até o final do mesmo (Experimento 2), as larvas morfologicamente não passaram do equivalente ao $3^{\circ}$ dia das larvas mantidas na salinidade controle. A tolerância mínima de salinidade para sobrevivência das larvas foi de 9 psu. Quando as larvas sobreviventes $(n=9)$ foram submetidas a 8 psu, todas morreram no mesmo dia.

\section{DISCUSSÃo}

As estrelas-do-mar da ordem Spinolosida, como as do gênero Echinaster, são conhecidas por apresentarem larvas lecitotróficas (Hyman, 1955). Larvas de Echinaster sepositus foram descritas por Lohner (1913) e Nachtshein (1914). Sidall (1979) descreveu o desenvolvimento larval de $E$. sentus. O desenvolvimento larval e crescimento de Echinaster echinophorus (Lamarck, 1816) foram descritos por Kempf (1966), no Nordeste da costa Brasileira. As larvas dessas espécies são semelhantes, embora apresentem variações quanto a coloração e ao tempo de desenvolvimento.

Atwood (1973) também observou o desenvolvimento larval de $E$. echinophorus e sugeriu que animais com morfo-tipos diferentes, mas da mesma área e mesmo habitat, poderiam desovar caracteristicamente dois tipos de ovos: 1) um ovo flutuante de coloração marrom escuro, que torna-se uma larva livre-natante; $e$ 2) um ovo laranja brilhante que se assenta imediatamente após a desova.

A hibridização das espécies de Echinasteré possível e pode ocorrer no ambiente natural (Watts et al 1982; Scheibling, 1982; Clark \& Downey, 1992). Watts et al (1982) induziram a hibridização em laboratório para estudar o efeito da salinidade e temperatura no desenvolvimento de espécies irmãs. Porém, estudos genéticos são necessários para distinguir mais claramente as diferentes espécies do gênero Echinasterou simplesmente expres-

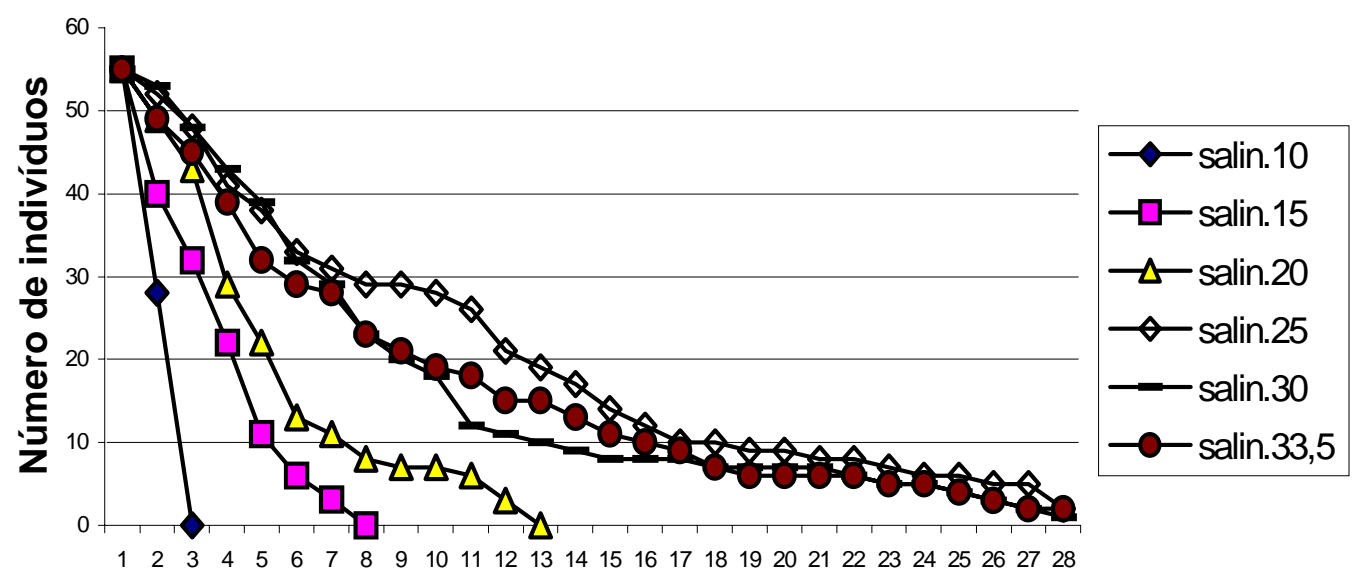

Dias de desenvolvimento

Figura 4: Curva de sobrevivência de Echinaster echinophorus em diferentes salinidades ao decorrer dos dias de desenvolvimento. 
sões fenotípicas que se manifestam como polimorfismos.

A presença de espécies polimórficas de Echinaster têm sido observadas na área da Praia das Conchas, Cabo Frio, Rio de Janeiro, Brasil. Campos-Creasey \& Nobre (em preparação) averiguaram o desenvolvimento larval de E. brasiliensis em laboratório e verificaram que o ovo desta espécie apresenta a coloração marrom escura, enquanto que aqui verifica-se que E. echinophorus apresenta seus ovos com coloração laranja brilhante. É possível que devido ao polimorfismo das espécies do gênero Echinaster haja uma confusão na literatura quanto as espécies observadas por outros autores anteriormente. Embora, somente estudos genéticos possam esclarecer a identificação específica dos diferentes morfo-tipos de Echinaster.

Atwood (1973) sugeriu que as larvas desenvolvidas a partir dos "ovos laranja" de $E$. echinophorus assentam-se mais rapidamente que as larvas geradas de "ovos marrons". Isto se assemelha com as observações realizadas neste estudo e com as observações das larvas de E. brasiliensis respectivamente. Ou seja, esta última espécie é a que apresenta ovos de coloração marrom escuro sendo que, quando da formação da larva, seu assentamento ocorre mais lentamente que em E. echinophorus (Campos-Creasey \& Nobre, em preparação). No entanto, neste trabalho foi observado que E. echinophorus apesar do ovo de coloração laranja que originou uma larva de vida livre natante, assentou-se apenas no $5^{\circ}$ dia de desenvolvimento.

Kempf (1966), registrou que os juvenis de $E$.echinophorus são resistentes a concentrações de salinidade de até $47 \mathrm{psu}$, alcançadas devido a problemas de evaporação em aquário. Em contraste, indivíduos adultos desta espécie podem ser encontrados em salinidades inferiores a 19 - 20 psu (Kempf, 1966). Este trabalho demonstrou que, assim como os adultos são tolerantes a salinidades baixas, as larvas de E. echinophorus podem atingir o desen- volvimento completo quando submetidas a salinidades até $25 \mathrm{psu}$.

A taxa de mortalidade foi mais intensa nos primeiros dias de desenvolvimento em todas as salinidades a que foram submetidas as larvas. Mesmo em salinidades tais como 25psu, o desenvolvimento completo foi atingido, embora mais lentamente (26 dias). Isto sugere que adultos que se reproduzam em regiões estuarinas geram larvas que podem permanecer nestas regiões e ali mesmo assentarem, sofrerem metamorfose e recrutarem. Porém, estas ficariam mais sujeitas à predação, pois seu tempo de permanência no plâncton seria maior. Por outro lado, esta tolerância a baixa salinidade, pode ser necessária para permitir que os ovos flutuantes tenham tempo de serem carreados fora da região estuarina para depois assentarem e sofrerem metamorfose.

Espécies do gênero Echinaster são exploradas comercialmente na costa do Rio de Janeiro, especialmente por aquarofilistas, mas também para fins religiosos. Campos-Creasey \& Nobre (em preparação), estimaram que as E. brasiliensis necessitariam de aproximadamente 14 anos para atingir um tamanho de $R=$ $50 \mathrm{~mm}$ (distância entre a boca e a extremidade do maior braço - Raio maior) se submetidas a condições de aporte nutricional reduzido e salinidade controle (33,5 psu). Por outro lado, larvas mantidas em aquário com filtro biológico de cascalho e salinidade de 33,5 psu, tiveram seu desenvolvimento completo e cresceram até $\mathrm{R}=20 \mathrm{~mm}$ em 1 ano, resultado semelhante ao encontrado por Scheibling (1982). Scheibling (1982) registrou o crescimento de duas populações de Echinaster (tipo I e tipo II) em condições de laboratório, sendo que a tipo I precisou de $41 / 2$ anos para atingir a forma adulta e a tipo II de $61 / 2$. Apesar destas estimativas terem sido realizadas com animais crescendo em laboratório, é muito provável que no ambiente natural o crescimento das espécies de Echinaster também seja lento.

Devido a possibilidade de hibridização entre as espécies de Echinaster é necessário um estudo genético para distinguí-las ou averi- 
guar o que são simplesmente expressões fenotípicas que se manifestam como polimorfismo, já que existe uma grande confusão na literatura quanto as espécies observadas por outros autores (Clark \& Downey 1992). Por esta razão e pelo lento crescimento (Scheibling, 1982 e Campos-Creasey \& Nobre, em preparação), torna-se crucial averiguar formas de promover desova e crescimento dessas espécies em laboratório, para compreender e distinguir a biologia de seu desenvolvimento, averiguar as taxas de crescimento afim de, pelo menos, repor os estoques de animais em áreas onde a extração é mais intensa.

\section{AGRADECIMENTOS}

Agradecemos aos estudantes da graduação do curso de Ciências Biológicas da Universidade Santa Úrsula os quais coletaram os animais adultos utilizados neste estudo ao cursarem a disciplina Equinodermos. Somos gratas ao biólogo Gerhard O. Peters pelos desenhos técnicos. Agradecemos especialmente a nossa Diretora de Pesquisa do Instituto de Ciências Biológicas da Universidade Santa Úrsula, Dra Jeanete Maron Ramos, por seu apoio em nos prover com instalações adequadas para o experimento e por promover as necessárias saídas de campo.

\section{REFERÊNCIAS BIBLIOGRÁFICAS}

Atwood, D. G. 1973.Larval development in the asteroid Echinaster echinophorus. Biol.Bull. 144:1-11.

Campos-Creasey, L.S. \& C.C. Nobre, Morphological changes in the larval development of Echinaster brasiliensis Müller \& Troeschel 1842 (Echinodermata: Asteroidea). (em preparação)

Chen, C.P. \& J.Q. Run.1988. Larval growth and bacteria-induced metamorphosis of Aracnoides placenta (L.) (Echinodermata: Echinoidea), p. 55-59. In: J.S. Ryland \& P.A. Tyler [Eds.], Reproduction, Genetics and Distribution of Marine Organisms. Denmark.

Clark, A.M. \& M.E. Downey. 1992. Starfishes of the Atlantic. Chapman \& Hall.

Hyman, L.H. 1955. The invertebrates: Echinodermata. Vol. IV, McGraw Hill Book Company 763pp.

Kempf, M., 1966. On the Development of Echinaster echinophorus (Lamarck). An. da Acad. Brasileira de Ciências 38: 505-507.

Löhner, L.R. 1913. Zur Entwicklungsgeschichte von Echinaster sepositus (Gray). Zool. Anz.. p. 41.

Nachtsheim, H. 1914. Über die Entwicklung von Echinaster sepositus (Gray). Zool. Anz. p. 44.

Scheibling, R.E. 1982. Differences in body size and groth rate between morphs of Echinaster (Echinodermata: Asteroidea) from the eastern Gulf of Mexico, p. 291298. In: J.M. Lawrence [Ed.], Echinoderms: Proceedings of the International Conference. Tampa Bay.

Sidall, S.E. 1979. Development of ossicles in juveniles of sea star Echinaster sentus. Bull. Mar. Science 29 (2): 278-282.

Tommasi, L.R. 1970. Lista dos asteróides recentes do Brasil. Bolm. I. Oceanogr. S.P. 18: 1-61.

Tommasi, L.R. 1999. Invertebrados Marinhos Registrados no Litoral Brasileiro Echinodermata Recentes e Fósseis do Brasil. Publicado na internet, site www.biotasp.org

Watts, S.A.; Scheibling, R.E.; Marsh, A.G. \& J.B. Mc Clintock. 1982. Effect of temperature and salinity on larval development of sibling species of Echinaster (Echinodermata: Asteroidea) and their hybrids. Biol.Bull. 163: 348-354. 